\title{
Computed Tomography of the Coronary Arteries
}

Authors: P.j. de Feyter MD, A. Weustink MD, F. Alberghina MD,

K. Gruszczynska MD, N. van Pelt MD, F. Pugliese MD, N. Mollet MD

Departments of Cardiology and Radiology, Erasmus Medical Center, Rotterdam, The Netherlands

Address for correspondence:

Prof. dr. P.j. de Feyter

Erasmus MC

Room Hs 207

PO Box 2040

3000 CA ROTTERDAM NL

Email:

p.j.defeyter@erasmusmc.nl

ABSTRACT MSCT CoronaryAngiography is a fast developing non-invasive diagnostic technique that can detect a coronary stenosis. The detection of a coronary stenosis is hampered by limited image quality and by motion artefacts and extensive calcifications. However, MSCT-coronary angiography is highly reliable to rule out coronary stenosis. The role of MSCT-coronary angiography in the diagnostic work-up of coronary artery disease needs further research.

\section{INTRODUCTION}

CT-coronary imaging is a robust technology which has a high tempora and spatial resolution allowing non-invasive visualization of the coronary plaque burden (coronary calcified and non-calcified plaques) and coronary lumen obstructions ${ }^{(1-3)}$. CT-coronary imaging has developed rapidly and is now poised to become a clinically reliable non-invasive diagnostic modality to assess the coronary lumen and coronary plaques. However, CT-coronary imaging is still fraught with limitations.
This article reviews the diagnostic utility and limitations of CT-coronary imaging.

\section{BASIC COMPUTED TOMOGRAPHY}

The gantry and patient couch are referred to as the scanner. The gantry is a mounted framework that surrounds the patients in a vertical plane ${ }^{(I)}$. It contains an $\mathrm{X}$-ray tube and a row of detectors which rotate around the patient, who is positioned in the center of the gantry (Figure I). The $\mathrm{X}$-ray tube produces a fan-shaped $\mathrm{X}$-ray beam which is collimated and passes through the patient and is collected on the detectors at the opposite side. The CT-uses $\mathrm{X}$-ray absorption to create images. Image contrast depends on the physical density and the number of atoms with differing atomic numbers. lodine and calcium have high atomic numbers, which is associated with high absorption and will appear white in CT-images. Hydrogen, which is abundant in fat, has a low atomic number and low absorption and appears dark grey. Blood and soft tissue containing hydrogen, oxygen and carbon appear light grey Lung tissue contains air and appears black. Each individual tomogram can be seen as a slice, which is composed of voxels, each of which contains a specific CT-number. Each CT-number is proportional to the absorption of $\mathrm{X}$-rays of tissue in that voxel. An image is reconstructed from the various CT-numbers within the slice. The CT-numbers are established on a relative basis, using the attenuation of water as a reference. The CTnumber for water is 0 , for air -1000 and for bone +1000 . A CT-image is reconstructed from CT-numbers obtained during a full rotation $\left(360^{\circ}\right)$ of the X-ray tube around the patient. Because the first and second halves of the $\mathrm{X}$-ray tube rotation provide comparable data partial scan $\left(180^{\circ}\right)$ reconstruction data, can be used that reduce the temporal resolution (see later) to half the $\mathrm{X}$-ray tube rotation time.

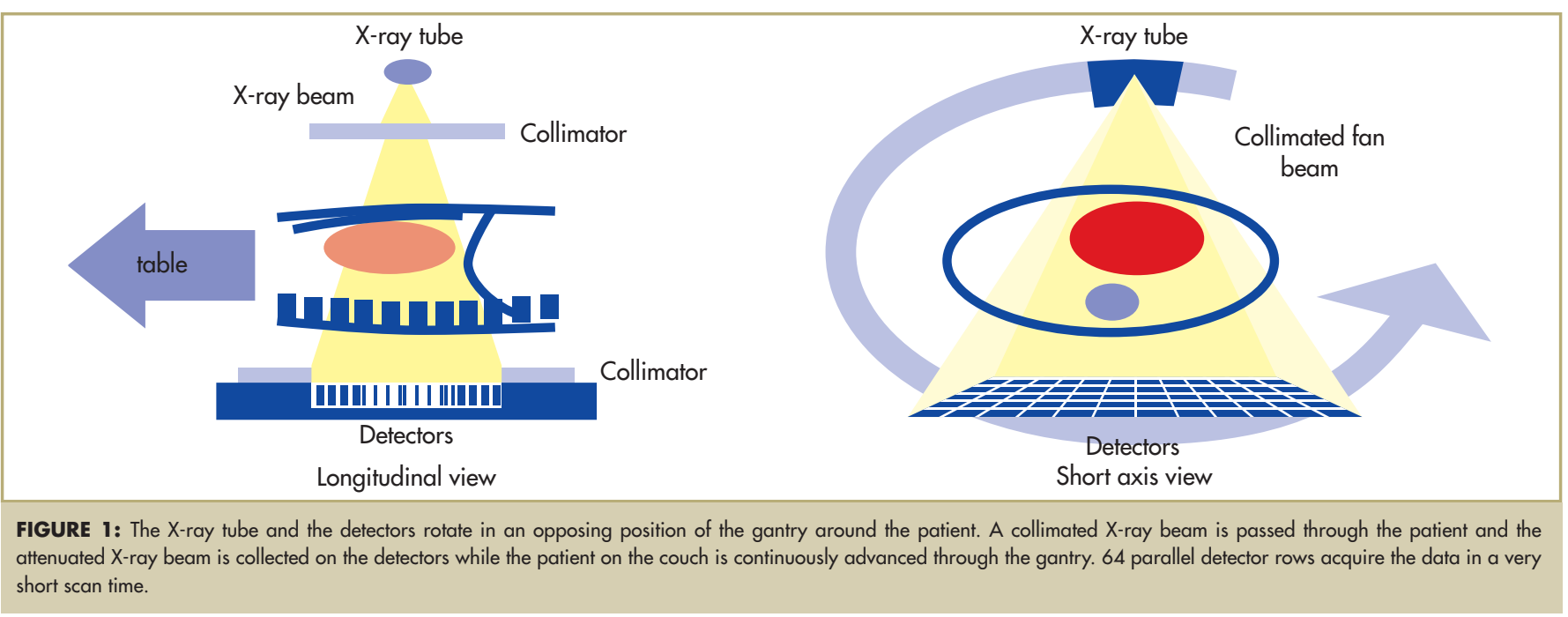


ECG-triggered scanning

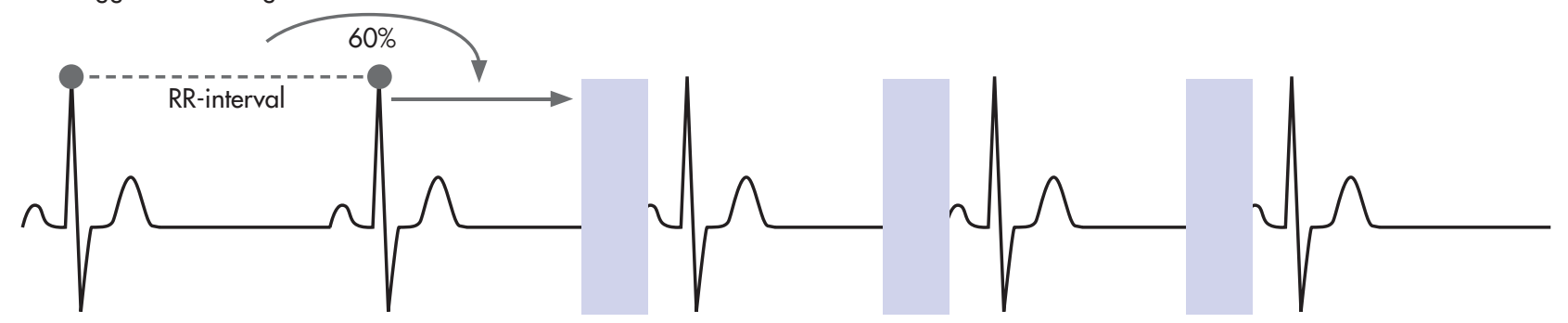

Continuous scanning
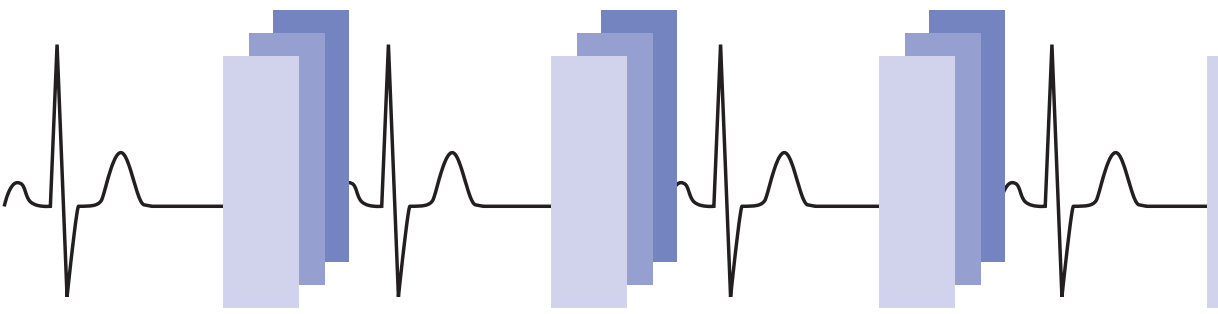

ECG-gated reconstructions

FIGURE 2: ECG-synchronized image reconstruction with sequential scan protocols uing prospective ECG triggering to synchronize the data acquisition and reconstruction window to the motion of the heart. Spiral CT scanning protocols acquire data continuously and record the ECG during the scan. Isocardiophasic images are reconstructed using retrospective ECGgating. The reconstruction window can be positioned anywhere within the R-R-interval.

Multislice CT-imaging is carried out either in the spiral mode or in the sequential mode. Multi-slice spiral CT is performed with the patient on the couch, continuously moving at a predefined speed through the scanner while the $\mathrm{X}$-ray tube and detectors rotate continuously around the patient. Thus a volumetric dataset is acquired from which crosssectional images can be reconstructed. In the sequential mode ("slice by slice") the table, and thus the patient, is moved incrementally between successive rotations of the X-ray tube ("step and shoot" approach).

Imaging of the heart requires acquisition or image reconstruction that is synchronized to the motion of the heart, to be able to reduce cardiac motion artefacts. This is achieved by simultaneously recording the ECG, which is used to synchronize prospective data acquisition or retrospective data reconstruction. In the sequential CT-mode the reconstruction window is determined by prospective triggering of the patient's ECG (Figure 2). In the spiral mode, the ECG signal is used to retrospectively, after data acquisition, select a cardiac motion-free dataset which mostly occurs in the diastolic phase of the cardiac cycle, but sometimes also in the systolic phase. Because spiral CT coronary angiography is associated with a rather high radiation exposure, the radiation exposure can be reduced by prospectively ECG-triggered X-ray tube modulation (see radiation exposure).

\section{CT IMAGE QUALITY}

Cardiac imaging suffers from cardiac motion-artefacts and, therefore, the data used for reconstruction of the coronary images are preferentially obtained from a relative cardiac motion-free period, which occurs mostly during the diastolic phase of the cardiac cycle.
Because the diastolic phase is longer during low heart rates ( $<60$ bpm), the optimal motion-free images are obtained during low heart rates, and therefore ß-blockers are usually given to reduce the higher heart rates $(>65 \mathrm{bpm})^{(4,5)}$.

Although the technical developments of CT have been spectacular, compared to the almost unbeatable high quality images of conventional invasive coronary angiography, the spatial resolution of 64-CT is still limited, but allows near isotropic resolution with voxel size of $0.4 \times 0.4$ $\times 0.4 \mathrm{~mm}^{3}$ (Table I).

TABLE I: Significant parameters of CT-coronary angiography compared to invasive coronary angiography

\begin{tabular}{l|c|c|c|}
\hline & 16-slice CT & 64-slice CT & $\begin{array}{c}\text { Invasive } \\
\text { Coronary } \\
\text { Angiography }\end{array}$ \\
\hline Spatial resolution & $0.8 \mathrm{~mm}$ & $0.4 \mathrm{~mm}$ & $0.2 \mathrm{~mm}$ \\
\hline Temporal resolution & $180-210 \mathrm{~ms}$ & $165 \mathrm{~ms}$ & $20 \mathrm{~ms}$ \\
\hline Contrast volume & $120 \mathrm{ml}$ & $80 \mathrm{ml}$ & $60 \mathrm{ml}$ \\
\hline Radiation exposure & $5-10 \mathrm{mSv}$ & $6-12 \mathrm{mSv}$ & $3-4 \mathrm{mSv}$ \\
\hline
\end{tabular}

The temporal resolution is of utmost importance when imaging the heart and plays a major role in the creation of motion-free cardiac images. The temporal resolution is defined as the duration of the reconstruction window during which time a slice is reconstructed (Figure 2).

The duration of the reconstruction window is related to the tuberotation speed and is half the time needed for the $X$-ray tube to rotate $360^{\circ}$ around the patient. Thus the faster the rotation speed the better the temporal resolution. 


\section{X-RAY RADIATION EXPOSURE}

CT-coronary imaging is associated with $\mathrm{X}$-radiation exposure, which is expressed as the effective dose.The effective dose reflects the potential biological effect of the radiation and is given in mSv (Sievert). The effective dose for various CT-examinations and scan protocols is presented in Table $2^{(6-9)}$

TABLE 2: Radiation exposure associated with cardiac CT-examination

\begin{tabular}{lcc} 
& \multicolumn{2}{c}{ Total - body effective dose mSv } \\
& male & female \\
\hline EBCT coronary calcium & 1.0 & 1.3 \\
\hline MDCT coronary calcium & $2.3-2.9$ & $3.2-3.6$ \\
\hline 16-slice CT coronary angiogram (no pulsing) & $7.9-11.8$ & $11.1-16.3$ \\
\hline 16-slice CT coronary angiogram (pulsing) & $4.0-6.2$ & $5.6-8.7$ \\
\hline 64-slice CT coronary angiogram (no pulsing) & $9.6-15.2$ & $13.5-21.4$ \\
\hline 64-slice CT coronary angiogram (pulsing) & $4.8-10$ & $6.8-14$ \\
\hline
\end{tabular}

Helical scanning is associated with higher radiation exposure than sequential scanning. Prospectively ECG triggered X-ray tube modulation does reduce the radiation exposure by about $40 \%$. Radiation exposure is reduced because the full tube current is only generated during a short time interval during a predefined period in diastole and reduced tube current during systole and early diastole. However, this mode is not very robust and relies on a stable heart rhythm, and the occurrence of an extrasystole during scanning may ruin the image quality. Furthermore, use of the tube modulation mode prevents data reconstruction during systole which, in approximately $30 \%$ of cases produces better image quality.

\section{CT-CORONARY CALCIFICATION IN ASYMPTOMATIC INDIVIDUALS}

CT-coronary calcification is imaged in the sequential mode using a lowdose radiation technique without contrast enhancement. The calcified coronary artery plaque is traditionally quantitated using the Agatston score in which the area of a calcific plaque with a CT-attenuation of more than $130 \mathrm{HU}$ is multiplied by a weighting factor that is based on the peak density of the calcified lesion (11). A factor of 1,2,3, or 4 has been assigned to calcium attenuation of I30-199HU, 200-299HU, 300$399 \mathrm{HU}$, or $>400 \mathrm{HU}$ respectively.

TABLE 3: Predictive value of CT-calcium of adverse cardiac events. Coronary Calcium Score

\begin{tabular}{l|ccccc} 
Author & $\begin{array}{c}\mathrm{N} \\
\text { subjects }\end{array}$ & $\begin{array}{c}\text { Calcium } \\
\text { score }\end{array}$ & $\begin{array}{c}\text { Prevalence } \\
(\%)\end{array}$ & $\begin{array}{c}\text { F-up } \\
\text { months }\end{array}$ & $\begin{array}{c}\text { Annual event } \\
\text { rate \% } \\
\text { (death, nonfatal/MI) }\end{array}$ \\
\hline Detrano & 1196 & $>0$ & 67 & 41 & 1.1 \\
\hline Raggi & 676 & $>0$ & 53 & 32 & 1.7 \\
\hline Kondos & 5635 & $>0$ & 60 & 37 & 0.3 \\
\hline Shaw & 10.377 & $\geq 11$ & 43 & 60 & 0.5 (all-cause death) \\
\hline Vliegenthart & 1795 & $>0$ & 63 & 40 & 0.2 \\
\hline Arad & 4903 & $>0$ & 49 & 52 & 0.2 \\
\hline Lamonte & 10.746 & $>100$ & 50 & 42 & 0.7 \\
\hline
\end{tabular}

The presence of coronary calcium is directly associated with the presence of coronary atherosclerosis and it has been shown that the presence of coronary calcium can predict adverse cardiac events, which is independent of and incremental to the presence of traditional risk factors $^{(1-17)}$ (Table 3).

Currently, the definitive role of CT-calcium scoring in asymptomatic individuals is not yet established. We will need more evidence from well-designed studies, such as the RECALL (Risk-factors Evaluation of Coronary caLcium and Life style), The Rotterdam Study and MESAstudy (Multi-Ethnic Study of Atherosclerosis), and CARDIA (Coronary Artery Risk Development in Young Adults) to better understand the additional role of calcium scoring for risk factor management in asymptomatic persons.

\section{MSCT CORONARY ANGIOGRAPHY: I6-SLICE CT-SCANNER}

The I6-slice MSCT scanner has a temporal resolution of $200 \mathrm{msec}$ and an in-plane resolution of $0.4 \times 0.4 \mathrm{~mm}$ with a slice thickness of $0.75 \mathrm{~mm}$ Comparative invasive angiographic studies have shown that the diagnostic performance of 16-slice MSCT coronary angiography to detect significant coronary stenosis is high, with sensitivities ranging from $67 \%$ to $98 \%$ and specificities from $79 \%$ to $98 \%{ }^{(18-31)}$ (Table 4 ) Pooling the results of these studies reveals an average sensitivity of $87 \%$ and a specificity of $96 \%$. This is achieved in approximately $92 \%$ of all coronary segments, while around $8 \%$ of the coronary segments were not analysable due to motion-artifacts or severe calcification. These limitations render the 16-slice CT-technique not reliable for routine clinical use and it is of note that the reported sensitivities and specificities were obtained in the larger proximal, mid and distal coronary segments that had lumen diameters of at least 1.5 to $2 \mathrm{~mm}$.

TABLE 4: Diagnostic performance of 16 CT-coronary angiography for detection of significant coronary stenosis (luminal diameter $>50 \%$ ): a coronary segmental analysis.

\begin{tabular}{|c|c|c|c|c|c|c|}
\hline Author & $\begin{array}{l}\text { Number } \\
\text { patients }\end{array}$ & $\begin{array}{c}\text { Excl. } \\
\text { Segments } \\
\%\end{array}$ & $\begin{array}{c}\text { Sensitivity } \\
\%\end{array}$ & $\begin{array}{c}\text { Specificity } \\
\%\end{array}$ & $\begin{array}{l}\text { PPV } \\
\%\end{array}$ & $\begin{array}{c}\text { NPV } \\
\%\end{array}$ \\
\hline Nieman & 58 & 0 & 95 & 86 & 80 & 97 \\
\hline Mollet ('04) & 127 & 7 & 92 & 95 & 79 & 98 \\
\hline Martuscelli & 72 & 16 & 89 & 98 & 90 & 98 \\
\hline Kuettner ('04) & 58 & 21 & 72 & 97 & 72 & 97 \\
\hline Leta & 31 & 12 & 75 & 91 & 65 & 94 \\
\hline Hoffmann** ('04) & 33 & 17 & 67 & 95 & 64 & 96 \\
\hline Mollet ('05) & 51 & 0 & 95 & 98 & 87 & 99 \\
\hline Kuettner & 72 & 7 & 82 & 98 & 86 & 97 \\
\hline Cademartiri & 40 & 0 & 96 & 96 & 86 & 99 \\
\hline Schuijf & 45 & 6 & 98 & 97 & 89 & 99 \\
\hline Kefer & 52 & 0 & 82 & 79 & 46 & 95 \\
\hline Hoffmann & 103 & 7 & 95 & 98 & 95 & 99 \\
\hline Kuettner & 120 & 7 & 85 & 98 & 93 & 95 \\
\hline Achenbach & 50 & 4 & 94 & 96 & 68 & 99 \\
\hline (weighted) & 912 & 7.8 & 87 & 96 & 81 & 97.5 \\
\hline
\end{tabular}

** stenosis $>70 \%$ PPV $=$ positive predictive value NPV = negative predictive value 


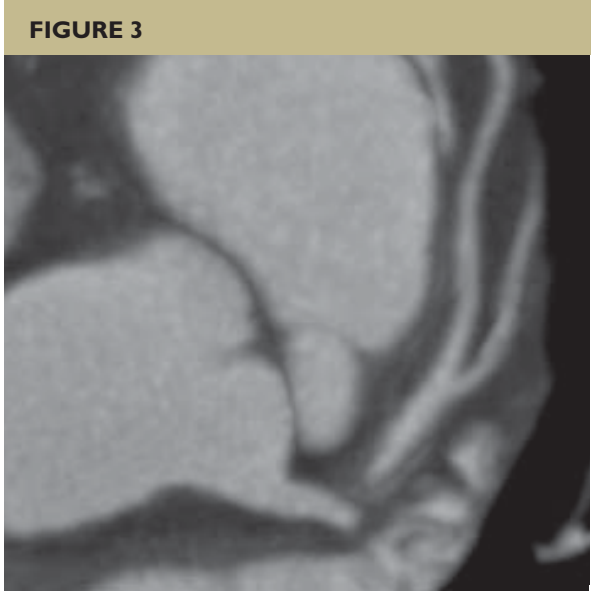

A: Severe proximal stenosis in left anterior descending coronary artery (axial slice).

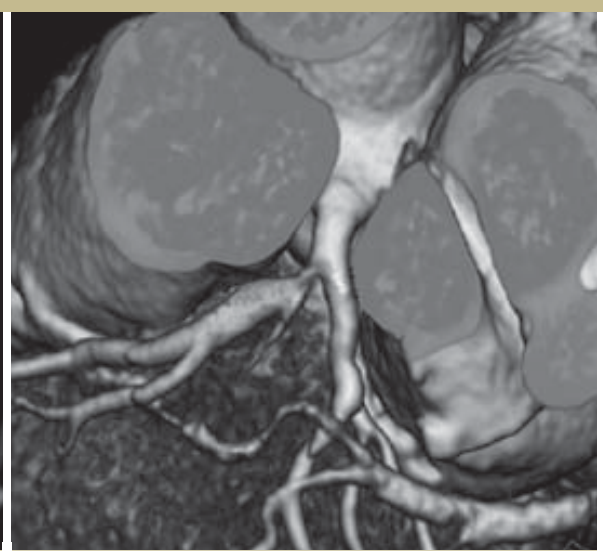

B: 3-dimensional reconstruction.

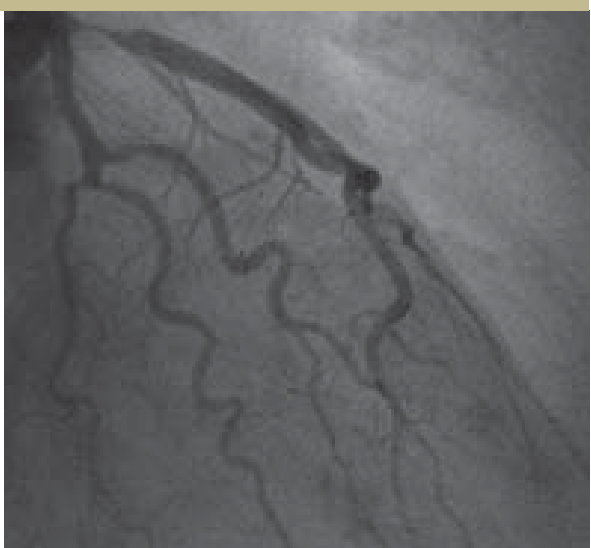

C: Corresponding invasive coronary angiogram.

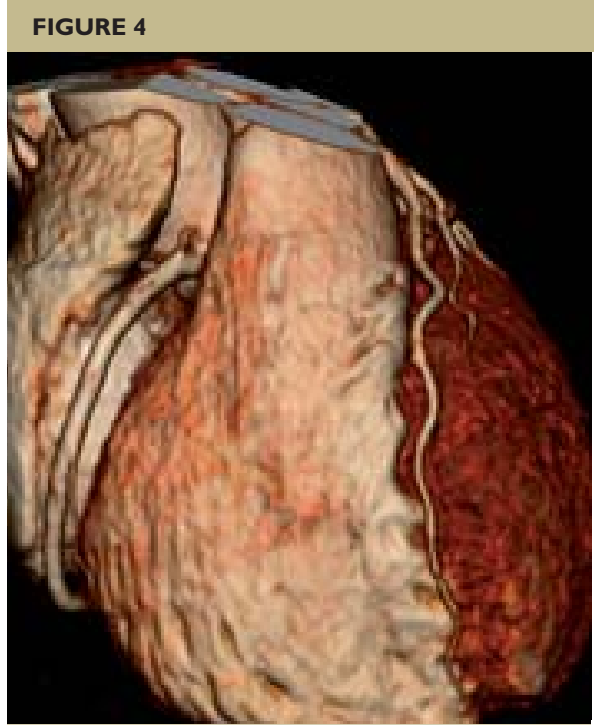

A: Three-dimensional reconstruction normal right coronary artery.

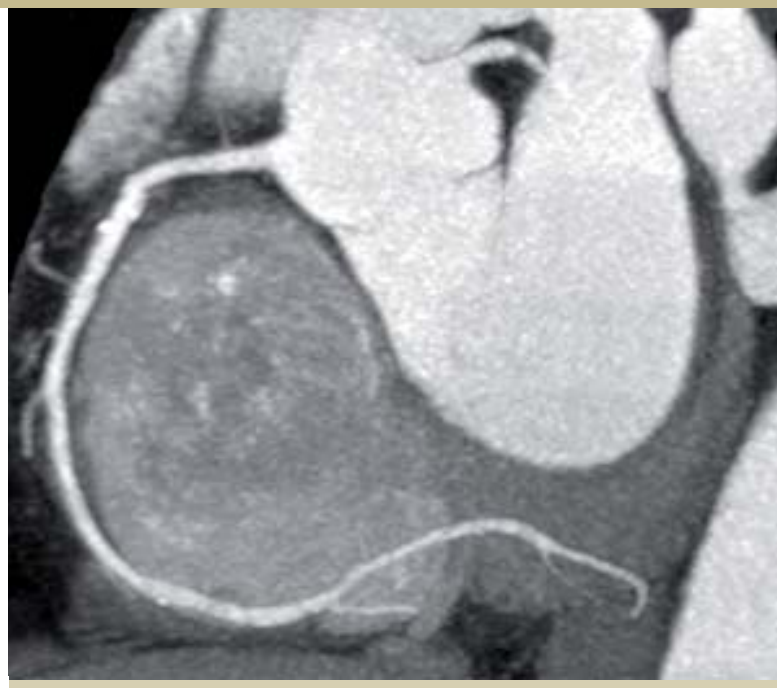

B: Axial slice.

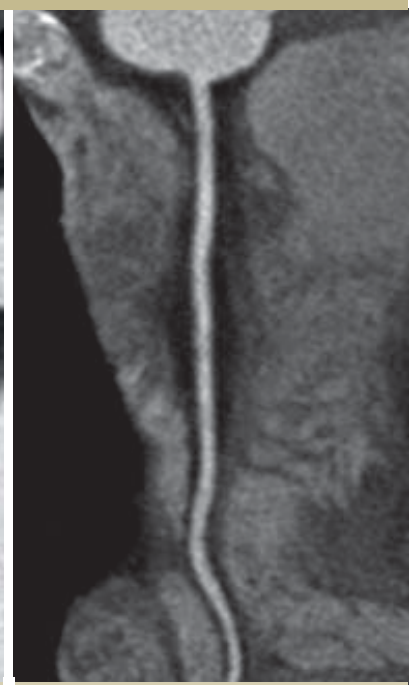

C: Multiplanar reconstruction.

\section{MSCT CORONARY ANGIOGRAPHY:}

\section{4-SLICE CT-SCANNER}

Significant technical advances in CT-technology have been introduced with almost unprecedented speed during the recent few years, which has culminated in the production of a 64-slice CT scanner which nowadays is available for clinical use and offered by the various vendors (Siemens, Philips, General Electronic and Toshiba). The 64-CT scanners from the various vendors differ slightly in design and configuration but all scanners feature a high temporal and spatial resolution and fast coverage of the entire heart with an acquisition time ranging from as low as 6 seconds to as high as 12 seconds. The diagnostic performance of the 64-slice CT-scanner when compared to quantitative invasive coronary angiography, to detect (Figure 3) or rule out (Figure 4) a significant coronary stenosis is shown in Tables 5 and $6^{(32-40)}$. The 64-sice CT-scanner still is not perfect but the high negative predictive value of 98\% underscores the reliability of CT to exclude the presence of significant coronary stenosis. Unfortunately, the 64-CT scanner still was not always able to analyse all coronary segments, and around $6 \%$ of coronary segments were excluded from analysis.

TABLE 5: Diagnostic performance of 64-slice CT coronary angiography to detect coronary stenosis ( $>50 \%$ luminal diameter: a segmental analysis)

\begin{tabular}{|l|c|c|c|c|c|c|}
\hline Author & $\begin{array}{c}\text { Number } \\
\text { patients }\end{array}$ & $\begin{array}{c}\text { Excl. } \\
\text { Segments } \\
\%\end{array}$ & $\begin{array}{c}\text { Sensitivity } \\
\%\end{array}$ & $\begin{array}{c}\text { Specificity } \\
\%\end{array}$ & $\begin{array}{c}\text { PPV } \\
\%\end{array}$ & $\begin{array}{c}\text { NPV } \\
\%\end{array}$ \\
\hline Leschka & 67 & 0 & 94 & 95 & 88 & 98 \\
\hline Leber & 55 & 0 & 76 & 97 & 75 & 97 \\
\hline Raff & 70 & 12 & 86 & 95 & 66 & 99 \\
\hline Mollet & 51 & 0 & 99 & 95 & 76 & 99 \\
\hline Ropers & 81 & 4 & 93 & 97 & 56 & 100 \\
\hline Schuijf & 60 & 1.4 & 85 & 98 & 82 & 96 \\
\hline Ong & 134 & 9.7 & 82 & 96 & 83 & 96 \\
\hline Ehara & 69 & 8 & 90 & 94 & 89 & 95 \\
\hline Nikolaou & 72 & 10 & 82 & 95 & 72 & 97 \\
\hline Total Weighted & 659 & 5.6 & 90 & 96 & 79 & 98 \\
\hline
\end{tabular}

$\overline{P P V}=$ positive predictive value $N P V=$ negative predictive value 


\begin{tabular}{|c|c|c|c|c|c|}
\hline Author & $\begin{array}{l}\text { Number } \\
\text { patients }\end{array}$ & $\begin{array}{c}\text { Sensitivity } \\
\%\end{array}$ & $\begin{array}{c}\text { Specificity } \\
\%\end{array}$ & $\begin{array}{l}\text { PPV } \\
\%\end{array}$ & $\begin{array}{l}\text { NPV } \\
\%\end{array}$ \\
\hline Leschka & 67 & 100 & 100 & 88 & 98 \\
\hline Leber & 45 & 88 & 85 & 75 & 97 \\
\hline Raff & 70 & 95 & 90 & 66 & 99 \\
\hline Mollet & 51 & 100 & 92 & 76 & 99 \\
\hline Ropers & 81 & 96 & 91 & 56 & 100 \\
\hline Schuijf & 60 & 94 & 97 & 97 & 93 \\
\hline Ehara & 67 & 98 & 86 & 98 & 86 \\
\hline Nikolaou & 68 & 97 & 79 & 86 & 96 \\
\hline Total (weighted) & 509 & 96 & 90 & 94 & 95 \\
\hline
\end{tabular}

PPV = positive predictive value NPV = negative predictive value

\section{CT-CORONARY ANGIOGRAPHY FOR ASSESSMENT OF CORONARY STENTS}

Assessment of coronary stents is extremely challenging. The stent struts create a blooming artefact which makes the stent struts much larger, thereby obscuring part of the in-stent lumen. Stent evaluation is usually limited to the assessment of stent patency which is quite reliable, but in particular, the smaller sized stents ( $\leq 3 \mathrm{~mm}$ in diameter) do not permit evaluation of the presence of neo-intimal hyperplasia or in-stent restenosis ${ }^{(4-45)}$.

However, the use of 64-slice CT-scanners has improved the visualization of stents, and now allows in-stent restenosis evaluation in larger sized stents (> 4mm in diameter) (Figure 5). A recent study demonstrated in 70 patients who underwent a follow-up study of patients who underwent left main stent implantation that a negative 64-slice CT-scan could reliably exclude the presence of in-stent restenosis ${ }^{(46)}$. This study suggested that 64-slice CT-ca could serve as an initial diagnostic modality to rule out the presence of in-stent restenosis in patients with left main stem stent implantation, while in case of a positive 64 CT-scan a confirmative invasive coronary angiogram is recommended because of the rather low positive predictive value of the scan.
TABLE 7: Diagnostic performance of 16 and 64-slice CT for the detection of bypass graft occlusion or non-occlusive obstruction and obstructions in native coronary ateries

\begin{tabular}{|c|c|c|c|c|}
\hline Author & Number & $\begin{array}{l}\text { Endpoint } \\
\text { patients }\end{array}$ & $\begin{array}{c}\text { Sensitivity } \\
\%\end{array}$ & $\begin{array}{c}\text { Specificity } \\
\%\end{array}$ \\
\hline \multirow[t]{2}{*}{ Martuscelli } & 96 & Occlusion & 100 & 100 \\
\hline & & Stenosis & 90 & 100 \\
\hline \multirow[t]{2}{*}{ Schlosser } & 51 & Occlusion & 100 & 100 \\
\hline & & Stenosis & 90 & 100 \\
\hline \multirow[t]{2}{*}{ Chiurlia } & 51 & Occlusion & 100 & 100 \\
\hline & & Stenosis & 96 & 100 \\
\hline \multirow[t]{2}{*}{ Moore } & 50 & Occlusion & 100 & 100 \\
\hline & & Stenosis & 100 & 99 \\
\hline \multirow[t]{3}{*}{ Salm } & 25 & Occlusion & 100 & 100 \\
\hline & & Stenosis & 100 & 94 \\
\hline & & Coronary stenosis & 100 & 89 \\
\hline \multirow[t]{3}{*}{ Nieman } & 24 & Occlusion & 100 & 98 \\
\hline & & Stenosis & 70 & 88 \\
\hline & & Coronary stenosis & 85 & 73 \\
\hline \multirow[t]{3}{*}{ Malagutti* } & 52 & Occlusion & 99 & 96 \\
\hline & & Stenosis & 89 & 93 \\
\hline & & Coronary stenosis & & \\
\hline
\end{tabular}

* 64-slice CT-scanner

\section{CT-CA FOR ASSESSMENT OF BYPASS PATIENTS}

The imaging of venous bypass grafts is less challenging because the grafts usually have a large diameter, are relative immobile and less calcified, but surgical metal clips causing significant CT-artefacts may cause problems with accurate assessment of adjacent disease. The detection of graft-occlusion using the 16-slice CT-scanner is quite reliable (Table 7) while the detection of non-occlusive stenoses is more problematic ${ }^{(47-53)}$. The 64-slice scanners perform slightly better, but evaluation of a post-bypass patient should include not only the bypass grafts but also the run-off native coronary segments distal to the graft anastomosis and non-grafted native coronary segments (Figure 6) Imaging of these coronaries is challenging because they usually are rather small, diffusely diseased and often heavily calcified.

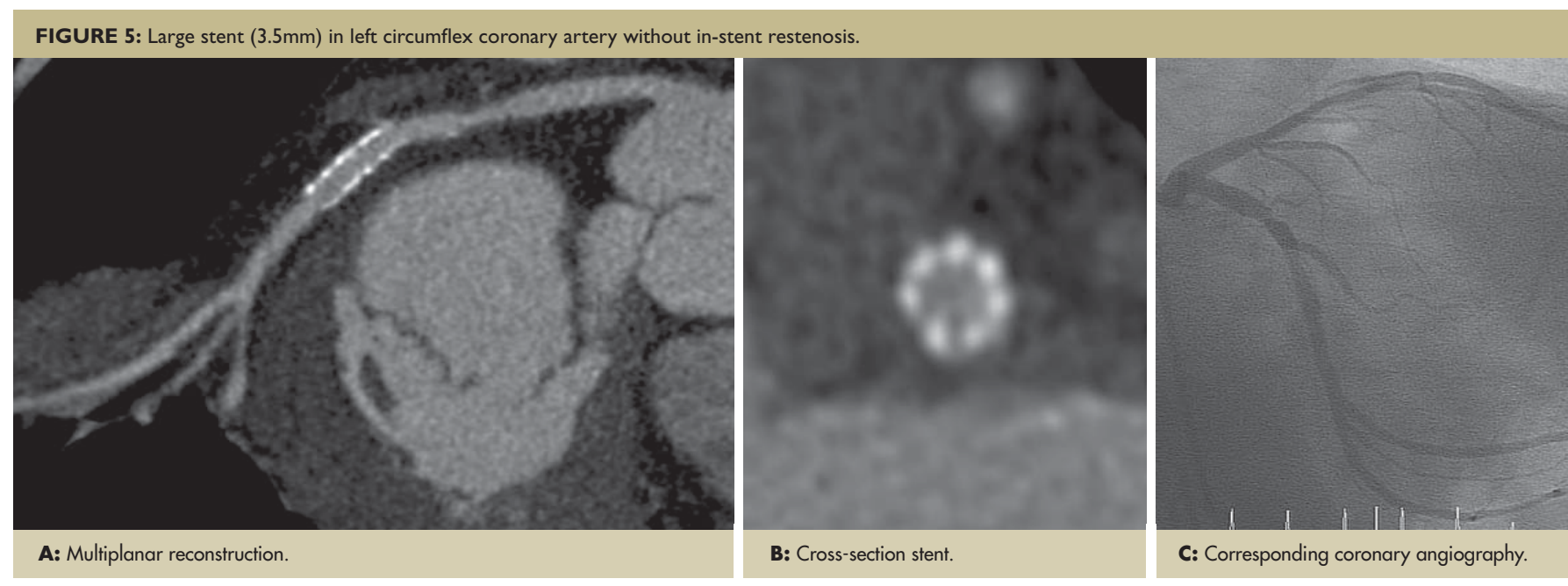




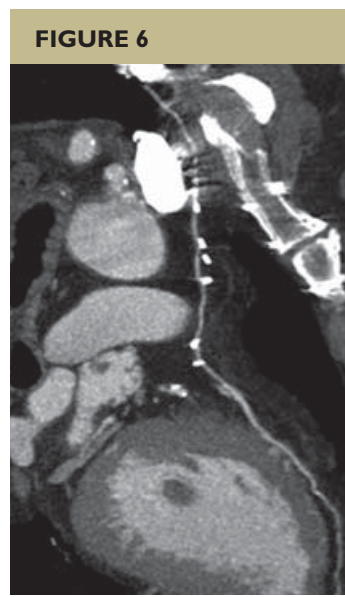

A: LIMA with anastomosis on left anterior descending coronary artery. Note: bright dots are surgical clip artefacts.

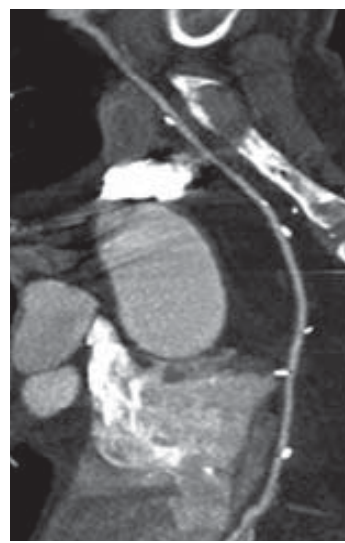

B: RIMA with anastomosis on the right coronary artery.

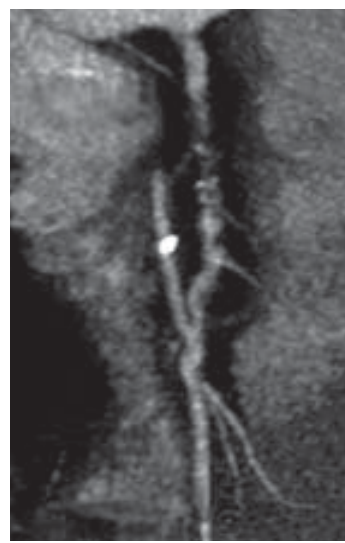

C: RIMA anastomosis and proximal occlusion of right coronary artery.

\section{LIMITATIONS OF MSCT CORONARY ANGIOGRAPHY}

Despite significant technological progress and increasing experience with the evaluation of MSCT coronary angiography, a number of shortcomings remain. CT-coronary angiography cannot be used in patients with persistent irregular heart rhythm (atrial fibrillation) or frequent extrasystoles which preclude reconstruction of coronary images. Severe calcification poses two problems: I) it obscures the underlying lumen and thus detection of an significant stenosis and 2) due to its blooming effects the severity of an adjacent stenosis may be overestimated. Fast heart rates (>70 bpm) are associated with cardiac motion-artifacts or unsharp images because the end-diastolic reconstruction time required for motion-free coronary reconstruction imaging is reduced. Reduction of the heart rate with oral or intravenous
B-blockade remedies this problem in the majority of the cases. The temporal resolution can be further reduced by use of bisegmental or multisegmental reconstruction algorithms that combine data from 2 or more cardiac cycles and thus prevent the occurrence of cardiac motion blurred images. However, these algorithms are most optimal when the heart rate is constant, the ECG signal is reliable and no arrhythmia occurs, since they rely on an identical cardiac contraction pattern with time-consistent positioning of the cardiac structures during each consecutive heart cycle.

\section{NEWEST CT-SCANNER:THE DUAL - SOURCE 64-CT}

The temporal resolution of CT-scanners is still limited and the cause of motion artefact of fast moving coronary segments. The dual-source CT scanner features a gantry composed of two $\mathrm{X}$-ray tubes placed at an orthogonal angle and each has an opposite detector row. This new CTconfiguration has improved the temporal resolution twofold as compared to a conventional scanner ${ }^{(54)}$. The initial results are impressive and demonstrate that, also at high heart rates, motion-free images can be obtained. Further studies are needed to evaluate its diagnostic performance.

\section{CARDIAC CT: EVOLVING INDICATIONS}

64-Slice CT-ca has now sufficient diagnostic accuracy to exclude significant coronary stenosis, suggesting that the technique is now ready to establish its role in the clinical work-up of patients presenting with chest pain. However, CT-ca is still limited and the technique fails in cases of persistent arrhythmia, frequent extra-systoles and severe segmental calcification, which may occur quite frequently alone or in combination in elderly populations (>70 years) where the incidence of symptomatic coronary artery disease is most frequent. Furthermore, a new technique would only be useful as a reliable alternative diagnostic technique if it is able to assess all relevant coronary segments and is not limited by the exclusion of non-evaluable segments due to motion artefacts or significant coronary calcifications. Currently CT-ca may be a viable technique in a limited number of clinical situations (Table 8).

TABLE 8: CT-ca as an alternative for invasive coronary angiography

I. coronary anomalies

2. patency bypass grafts

3. exclusion of significant $C A D$ in patients referred for cardiac valve surgery

4. exclusion of significant $C A D$ in patients with a low or intermediate pretest-risk

5. exclusion of in-stent restenosis in stents implanted in left main stem

\section{ABBREVIATIONS}

CT Computed Tomography

HU Hounsfield Units

MSCT Multi-Slice Computed Tomography

CT-ca Computed Tomography Coronary Angiography 


\section{REFERENCES:}

I. De Feyter PJ, Krestin GP, Cademartiri F, et al. Computed Tomography of the Coronary Arteries. Taylor \& Francis LTD, 2005. ISBN I84| 84439.

2. Nieman $K$, Oudkerk M, Rensing BJ, et al. Coronary angiography with multi-slice computed tomography. Lancet 200 I;357:599-603.

3. Achenbach S, Giesler T, Ropers D, et al. Detection of coronary artery stenoses by contrast-enhanced, retrospectively electrocardiographically-gated, multislice spiral computed tomography. Circulation 200 I; 103:2535-8.

4. Giesler T, Baum U, Ropers D, et al. Noninvasive visualization of coronary arteries using contrast-enhanced multidetector CT: influence of heart rate on image quality and stenosis detection. AR Am J Roentgenol. 2002; 179:91।-916.

5. Nieman K, Rensing B], van Geuns RJ, et al. Non-invasive coronary angiography with multislice spiral computed tomography: impact of heart rate. Heart. 2002;88:470-474.

6. Morin RL, Gerber TC, McCollough CH. Radiation Dose in Computed Tomography of the Heart. Circulation 2003; 107:917 - 922.

7. Hunold P,Vogt FM, Schmermund A, et al. Radiation exposure during cardiac CT: effective doses at multi-detector row CT and electron-beam CT. Radiology 2003; 226: I 45- I 52

8. Jakobs TF, Becker CR, Ohnesorge B, et al. Multislice helical CT of the heart with retrospective ECG gating: reduction of radiation exposure by ECG-controlled tube current modulation. Eur Radiol. 2002; 12:1081-6.

9. Trabold T, Buchgeister M, Kuttner A, et al. Estimation of radiation exposure in 16 detector row computed tomography of the heart with retrospective ECG-gating. Rofo Fortschr Geb Rontgenstr Neuen Bildgeb Verfahr. 2003; I 75: I 05 I -5.

10. Detrano RC, Doherty R, Wong, ND, et al. Coronary calcium does not accurately predict near-term future coronary events in high-risk adults. Circulation 1999:99:2633-38

II. Agatston AS, Janowitz WR, Hildner FJ, et al. Quantification of coronary artery calcium using ultrafast computed tomography. I Am Coll Cardiol. 1990 Mar I5; I 5(4):827-32.

12. Raggi P, Callister TQ, Cooil B, et al. Identification of patients at increased risk of firs unheralded acute myocardial infarction by electron-beam computed tomography. Circulation. 2000 Feb 29; 10 I (8):850-5.

13. Kondos G, Hoff JA, Sevrukov A, et al. Electron-Beam Tomography Coronary Artery Calcium and Cardiac Events. Circulation 2003; 107:257|-2576.

14. Shaw LJ, Raggi P, Schisterman E, et al. Prognostic value of cardiac risk factors and coronary artery calcium screening for all-cause mortality. Radiology. 2003 Sep;228(3):826-33.

15. Vliegenthart R, Oudkerk M, Hofman A, et al. Coronary calcification improves cardiovascular risk prediction in the elderly. Circulation. 2005 Jul 26; I I 2(4):572-7. Epub 2005 Jul I I

16. Arad Y, Goodman KJ, Roth M, et al. Coronary calcification, coronary disease risk factors, C-reactive protein, and atherosclerotic cardiovascular disease events: the St. Francis Heart Study. J Am Coll Cardiol. 2005 Jul 5;46( I): 158-65.

17. LaMonte MJ, FitzGerald S). Church TS, et al. Coronary artery calcium score and coronary heart disease events in a large cohort of asymptomatic men and women. Am Epidemiol. 2005 Sep 1; | 62(5):421-9.

18. Nieman K, Cademartiri F, Lemos PA, et al. Reliable noninvasive coronary angiography with fast submillimeter multislice spiral computed tomography. Circulation 2002; 106:205।-4.

19. Mollet NR, Cademartiri F, Nieman K, et al. Multislice spiral computed tomography coronary angiography in patients with stable angina pectoris. J Am Coll Cardio 2004:43:2265-70.

20. Martuscelli E, Romagnoli A, D'Eliseo A, et al.Accuracy of thin-slice computed tomography in the detection of coronary stenoses. Eur Heart | 2004;25: I 043-8.

21. Kuettner A, TraboldT, Schroeder S, et al. Noninvasive detection of coronary lesions using 16-detector multislice spiral computed tomography technology: initial clinical results. Am Coll Cardiol 2004:44:1230-7.

22. Leta R, Carreras F, Alomar $X$, et al. Non-invasive coronary angiography with 16 multidetector-row spiral computed tomography: a comparative study with invasive coronary angiography. Rev Esp Cardiol 2004;57:217-24

23. Hoffmann U, Moselewski F, Cury RC, et al. Predictive value of I6-slice multidetector spiral computed tomography to detect significant obstructive coronary artery disease in patients at high risk for coronary artery disease: patient- versus segment-based analysis. Circulation 2004; I 1 0:2638-43.

24. Mollet NR, Cademartiri F, Krestin GP, et al. Improved diagnostic accuracy with I6-row multi-slice computed tomography coronary angiography. I Am Coll Cardio 2005;45: 1 28-32.

25. Kuettner A, Beck T, Drosch T, et al. Diagnostic accuracy of noninvasive coronary imaging using |6-detector slice spiral computed tomography with $188 \mathrm{~ms}$ temporal resolution. J Am Coll Cardiol 2005;45: 123-7.

26. Cademartiri F, Runza G, Marano R, et al. Diagnostic accuracy of 16-row multislice CT angiography in the evaluation of coronary segments. Radiol Med (Torino) 2005; 109:91-7.

27. Schuiif JD, Bax ل| Salm LP, et al. Noninvasive coronary imaging and assessment of left ventricular function using |6-slice computed tomography. Am J Cardiol 2005;95:57 I-4
28. Kefer J. Coche E, Legros G, et al. Head-to-head comparison of three-dimensiona navigator-gated magnetic resonance imaging and 16-slice computed tomography to detect coronary artery stenosis in patients. Am Coll Cardiol 2005;46:92-100.

29. Hoffmann $\mathrm{MH}$, Shi H, Schmitz BL, et al. Noninvasive coronary angiography with multislice computed tomography. Jama 2005;293:247। -8.

30. Kuettner A, BeckT, Drosch T, et al. Image quality and diagnostic accuracy of non-invasive coronary imaging with 16 detector slice spiral computed tomography with $188 \mathrm{~ms}$ temporal resolution. Heart 2005;91:938-41.

31. Achenbach S, Ropers D, Pohle FK, et al. Detection of coronary artery stenoses usin multi-detector CT with $16 \times 0.75$ collimation and 375 ms rotation. Eur Heart 2005;26:1978-86.

32. Leschka S, Alkadhi H, Plass A, et al. Accuracy of MSCT coronary angiography with 64-slice technology: first experience. Eur Heart J 2005;26: 1 482-7.

33. Leber AW, Knez A, von Ziegler F, et al. Quantification of obstructive and nonobstructive coronary lesions by 64-slice computed tomography: a comparative study with quantitative coronary angiography and intravascular ultrasound. J Am Coll Cardio 2005:46: |47-54

34. Raff GL, Gallagher MJ, O'Neill WW, et al. Diagnostic accuracy of noninvasive coronary angiography using 64-slice spiral computed tomography. I Am Coll Cardio 2005;46:552-7

35. Mollet NR, Cademartiri F, van Mieghem CA, et al. High-resolution spiral computed tomography coronary angiography in patients referred for diagnostic conventiona coronary angiography. Circulation 2005; 1 12:23 18-23.

36. Ropers D, Rixe J, Anders K, et al. Usefulness of multidetector row spiral computed tomography with 64- $\times 0.6-\mathrm{mm}$ collimation and 330-ms rotation for the noninvasive detection of significant coronary artery stenoses. Am J Cardiol. 2006 Feb 1;97(3):343-8

37 Schuijf JD, Mollet NR, Cademartiri F, et al. Do risk factors influence the diagnostic accuracy of noninvasive coronary angiography with multislice computed tomography? | Nucl Cardiol. 2006 Sep; | 3(5):635-4 |

38. Ong TK, Chin SP, Liew CK, et al. Accuracy of 64-row multidetector computed tomography in detecting coronary artery disease in 134 symptomatic patients: influence of calcification. Am Heart J. 2006 Jun; I 5 I (6): I 323.e I-6.

39. Ehara M, Surmely JF, Kawai M, et al. Diagnostic Accuracy of 64-Slice Computed Tomography for Detecting Angiographically Significant Coronary Artery Stenosis in an Unselected Consecutive Patient Population. Circulation J 2006; 70:564-57I.

40. Nikolaou K, Flohr T, Knez A, et al. Advances in cardiac CT imaging: 64-slice scanner. Int | Cardiovasc Imaging. 2004 Dec;20(6):535-40.

41. Gilard M, Cornily JC, Pennec PY, et al. Assessment of coronary artery stents by 16 slice computed tomography. Heart. 2006 Jan;92( 1):58-61. Epub 2005 Apr 21.

42. Schuijf JD, Bax JJ, Jukema JW, et al. Feasibility of assessment of coronary stent patency using | 6-slice computed tomography. Am J Cardiol. 2004 Aug 15;94(4):427-30

43. Cademartiri F, Mollet N, Lemos PA, et al. Usefulness of multislice computed tomographic coronary angiography to assess in-stent restenosis. Am J Cardiol. 2005 Sep 15;96(6):799-802

44. Gaspar T, Halon DA, Lewis BS, et al. Diagnosis of Coronary In-stent Restenosis With Multidetector Row Spiral Computed Tomography. IACC 2005:46: I 573-79.

45. Gilard M, Cornily JC, Rioufol G, et al. Noninvasive assessment of left main coronary stent patency with 16-slice computed tomography. Am J Cardiol. 2005 Jan 1;95( I):1 10-2

46. Van Mieghem CA, Cademartiri F, Mollet NR, et al. Multislice spiral computed tomography for the evaluation of stent patency after left main coronary artery stenting: a comparison with conventional coronary angiography and intravascular ultrasound. Circulation. 2006 Aug 15; I 14(7):645-53. Epub 2006 Aug 7.

47. Martuscelli E, Romagnoli A, D'Eliseo A, et al. Evaluation of venous and arterial conduit patency by |6-slice spiral computed tomography. Circulation. 2004 Nov I 6; I 10(20):3234-8.

48. Schlosser T, Konorza T, Hunold $\mathrm{P}$, et al Noninvasive visualization of coronary artery bypass grafts using 16-detector row computed tomography. J Am Coll Cardiol. 2004 Sep 15;44(6): 1224-9

49. Chiurlia E, Menozzi M, Ratti C, et al. Follow-up of coronary artery bypass graft patency by multislice computed tomography. Am J Cardiol. 2005 May 1;95(9): 1094-7.

50. Moore RK, Sampson C, MacDonald S, et al. Coronary artery bypass graft imaging using ECG-gated Multislice computed tomography comparison with: catheter angiography. Clinical Radiology 2005;60:990-8

5I. Salm LP, Bax J], Jukema JW, et al. Comprehensive assessment of patients after coronary artery bypass grafting by 16-detector-row computed tomography. Am Heart J. 2005 Oct; | 50(4):775-8|

52. Nieman K, Pattynama PM, Rensing B], et al. Evaluation of patients after coronary artery bypass surgery: CT angiographic assessment of grafts and coronary arteries. Radiology 2003 Dec;229(3):749-56.

53. Malagutti P, Nieman K, Meijboom WB, et al. Use of 64-slice CT in symptomatic patients after coronary bypass surgery: evaluation of grafts and coronary arteries. Eur Heart 2006 Jul 17

54. Johnson TR, Nikolaou K, Wintersperger B], et al. Dual-source CT imaging: initia experience. Eur Radiol 2006; 16:1409-1415 